\title{
A Systematic Review of Multimodal Non- Pharmacological Interventions for Cognitive Function in Older People with Dementia in Nursing Homes
}

\author{
Kyosuke Yorozuyaa, b Yuta Kubo ${ }^{c}$ Naoki Tomiyamac Shingo Yamane ${ }^{b}$ \\ Hideaki Hanaokab \\ ${ }^{a}$ Rehabilitation Unit, Hagijisei Hospital, Hagi, Japan; ${ }^{\mathrm{b}}$ Graduate School of Biomedical and \\ Health Science, Hiroshima University, Hiroshima, Japan; ' ${ }^{C}$ Faculty of Care and Rehabilitation, \\ Seijoh University, Tokai, Japan
}

\section{Keywords}

Multimodal · Non-pharmacological interventions · Cognitive function · Older people with dementia $\cdot$ Nursing home

\begin{abstract}
Introduction: Multimodal non-pharmacological interventions (MNPIs) have been reported to be effective in improving the cognitive function. Therefore, it is necessary to study these interventions in older people with dementia (PWD) in nursing homes (NHs). Aims: This study aimed to investigate the effects, contents, frequency, duration, length, and form of MNPIs on the global and specific cognitive functions of PWD in NHs through a systematic review, and to consider what kind of intervention design is most effective. Methods: A systematic search of peer-reviewed literature published between January 2008 and October 2018 was performed on the PubMed, Cochrane Library, Web of Science and CINAHL databases. Results: Six randomized controlled trials (RCTs) and one non-RCTs were extracted from electronic databases, and a review was carried out. Conclusion: Our review suggests that MNPIs may improve the global, executive function and memory of PWD in NHs. The combination of exercise, cognitive training and activities of daily living, and intervention at least 3 times a week over at least 8 weeks with, at least 30 min per session using the integrated form is recommended for improving the global and specific cognitive functions of PWD in NHs.
\end{abstract}


Yorozuya et al.: Review of MNPIs for Dementia

\section{Introduction}

Residents in nursing homes (NHs) tend to experience a decline in cognitive function [1], which may decrease the quality of life [2]. Furthermore, cognitive deterioration of older people with dementia (PWD) in NHs may lead to behavioral disorders such as agitation and aggressive behavior. This could cause major problems such as physical, mental, and economic burden on PWD and their caregivers, and from a social aspect, increase the cost of medical and nursing care [3-6]. Improving the cognitive function of PWD in NHs may help solve these problems; however, this is challenging.

Options aiming to improve the cognitive function include both pharmacological and nonpharmacological interventions (NPI). Although pharmacological intervention has reported improvements in cognitive function [7-9], there are also adverse side effects such as nausea, weight loss and leg cramps, and increased mortality risk at the same time [10-14]. Therefore, further development of NPI, which is expected to have the same beneficial effect as pharmacological intervention, is required $[15,16]$.

In NPIs for the cognitive function of PWD, improvement using a single intervention such as reminiscence, music, and cognitive training have been reported [17-19]. However, with single interventions, the effects on multiple specific cognitive functions such as memory, executive function, and visuospatial function [20-22] that require preferential intervention in dementia may be partial, and concern has also been raised that the effect may not be sufficient for global cognitive functions [23, 24].

In recent years, positive effects of multimodal non-pharmacological intervention (MNPI), which combines different NPIs, on the cognitive function of PWD in NHs have been reported [25-27]. Many MNPIs are aimed primarily at improving global cognitive function [18, 27, 28]. In addition, improvements in specific cognitive functions such as word list registration and phonological verbal fluency have been reported along with global cognitive functions [26, 29]. It has also been mentioned that many have a synergistic effect on improving the cognitive function $[25,27,30]$. MNPI may also involve compensatory mechanisms that improve global cognitive function [26, 31,32]. Therefore, MNPI for PWD is more likely to obtain the desired effects on global and several specific cognitive functions than a single intervention, and therefore, could delay cognitive decline.

However, many of the reported MNPIs are not designed using a theoretical model that clearly addresses questions such as "what kind of intervention is effective for which global and specific cognitive function" $[18,24]$. In addition, there are few previous studies and insufficient evidence for verification. Furthermore, it is not clear what frequency, duration, length, and form (whether a different intervention was an integrated form, divided form or both forms) are recommended for a MNPI [24].

Regarding the subjects of MNPI, systematic reviews on MNPIs targeting PWD have focused on PWD living in both the community and in facilities $[18,33]$. To the best of our knowledge, no review of MNPI has been conducted on PWD living only in facilities. Previous studies have mentioned the necessity to distinguish NPIs in a systematic review, targeting PWD in a facility separately from those in the community, since the available resources, severity of cognitive impairment and complications differ between subjects living in the community and in those living in a facility $[34,35]$. In addition, NHs have different characteristics of standards and residents compared with facilities such as group living homes [36]. Furthermore, most PWD are eventually placed in a NH [1,37]. Mindful of these points, it is necessary to review only those studies that include residents in NHs. Therefore, this study aimed to investigate the effects, contents, frequency, duration, length, and form of MNPI on the global and specific cognitive functions of PWD in NHs by systematic review and to consider what kind of intervention design is most effective. 
Yorozuya et al.: Review of MNPIs for Dementia

\section{Methods}

Methodology

In terms of MNPI, "multimodal" [28], "multidomain" [29], "multicomponent" [15], "integrated" [38] have been used, but the definition of such terms varies depending on the author, research question, country, and other factors. In this study, the term "multimodal" was used based on recent studies [28, 33]. MNPI was defined as "an intervention composed of 2 or more different NPIs."

NPIs used in the MNPI were classified as "exercise," "reminiscence," "art," "horticulture," "music," "cognitive training," and "others" according to previous studies [25, 29, 38, 39]. In other previous studies [40-42], "exercise" was classified as "aerobic," "strength" and "stretching" and reported as one MNPI; therefore, each of these was also classified as one intervention in our review.

This study was conducted according to the preferred reporting items for systematic reviews and metaanalyses statement [43-45].

\section{Inclusion Criteria}

All studies included in this review met the following inclusion criteria: (1) randomized controlled trial (RCT) or non-RCT; (2) participants were recruited from NHs; (3) diagnostic criteria or operational definition of dementia was described; (4) MNPI was used; (5) the effects of MNPIs were evaluated for reliability and validity for global cognitive functions or specific cognitive functions; (6) the effects of intervention were statistically analyzed; and (7) the paper was written in English.

\section{Exclusion Criteria}

The following exclusion criteria were applied: (1) case reports; (2) short reports; (3) 1 or more interventions for facility staff or family caregivers were included in the composition of the MNPI (in one systematic review of NPIs for dementia, MNPIs for care staff and family caregivers were positioned as different interventions; in addition, the recommended grade was also different) [18]; and (4) 1 or more pharmacological interventions were included in the composition of the MNPI.

Some of the extracted studies conducted by the same team and/or at the same NH were included in the review if different subjects and methods were used and the study fit the inclusion criteria.

Search Strategy

A systematic search of peer-reviewed literature published between January 2008 and October 2018 was performed on the PubMed, Cochrane Library, Web of Science and Cumulative Index to Nursing and Allied Health Literature (CINAHL) databases. The first author (K.Y.) extracted search terms from the United States National Library of Medicine and existing literature.

Search terms were as follows: (NHs * OR long term care facilities*) AND (neurocognitive disorders * OR dementia * OR cognition disorders*) AND (aged * OR elder people * OR elderly person * OR older people * OR older adults * OR old person* OR residents*).

\section{Selection Process}

Initial screening. The first author and the second author (K.Y. and Y.K.) independently selected potential papers from the title and/or abstract. If any discrepancies occurred between the two authors, the third author (N.T.) was asked to make a decision.

Secondary screening. The first author and the fourth author (K.Y. and S.Y.) independently selected papers considered in the initial screening. Papers to include in our study were identified by reading the full text of the paper. If any discrepancies occurred between the 2 authors, the last author (H.H.) was asked to make a decision.

\section{Data Extraction}

For data extraction, two authors (K.Y. and S.Y.) independently extracted the data from the collected papers. If any discrepancies occurred between the two authors, the last author (H.H.) was asked to make a decision.

\section{Outcomes}

The primary outcomes included the global and specific cognitive functions (e.g., memory, executive function) of PWD in NHs. The secondary outcomes included behavioral disorders and psychological functions (e.g., behavioral and psychological symptoms of dementia, quality of life). 
Yorozuya et al.: Review of MNPIs for Dementia

Methodological Quality Assessment

The first author and the fourth author (K.Y. and S.Y.) independently evaluated the quality of the research.

Randomized Controlled Trials

The Modified Jadad Scale was used [46-48]: (1) was the study described as randomized?; (2) was the study described as double-blinded?; (3) was there a description of withdrawals and drop outs?; (4) was there a clear description of the inclusion and exclusion criteria?; (5) was the method used to assess adverse effects described?; (6) were the methods of statistical analysis described?

Scale scores range from 0 to 8 points. Scores of $0-3$ signified low-quality while scores of 4-8 signified high-quality.

\section{Non-RCTs}

The methodological index for non-randomized studies was used [49]: (1) a clearly stated aim; (2) inclusion of consecutive patients; (3) prospective collection of data; (4) endpoints appropriate to the aim of the study; (5) unbiased assessment of the study endpoint; (6) follow-up period appropriate to the aim of study; (7) loss to follow-up <5\%; (8) prospective calculation of the study size; (9) an adequate control group; (10) contemporary groups; (11) baseline equivalence of groups; and (12) adequate statistical analyses.

Items 1-8 are applicable to non-comparative studies and items 1-12 are applicable to comparative studies. The global ideal scores for non-comparative studies and comparative studies are 16 and 24, respectively.

\section{Level of Evidence}

For each selected study, the evidence level was also determined based on the criteria of Shekelle et al. [50].

Classification Schemes

Category of evidence was determined as follows [50]: evidence for meta-analysis of RCT, Ia; evidence from at least one RCT, Ib; evidence from at least one controlled study without randomization, IIa; evidence from at least one other type of quasi-experimental study, Ilb; evidence from non-experimental descriptive studies, such as comparative studies, correlation studies, and case-control studies, III; evidence from expert committee reports or opinions or clinical experience of respected authorities, or both, IV.

Investigation of Intervention Design

Outcome of MNPI

From each selected study, the outcomes used for the MNPI were extracted.

\section{Effect of MNPI}

From each selected study, the outcomes with significant improvement effects were clarified and an investigation of the effects of MNPI was conducted.

Contents of MNPI

From each selected study, the types and trends of NPIs used for the MNPI were identified and an investigation of an effective combination performed.

Frequency, Duration, and Length of MNPI

From each selected study, the average and maximum and minimum values for the frequency, duration, and length of MNPI were identified.

Form of MNPI

Three forms of MNPI have been reported. The first is an integrated form in which multiple types of intervention are performed as one integrated intervention, the second is a divided form in which multiple types of intervention are performed separately, and the third is both of these forms combined [29, 38, 51].

From each selected study, researchers clarified whether the composition of the MNPIs was integrated, divided or both forms, and investigated the effective form of the MNPI. 
Dementia

and Geriatric
Cognitive Disorders

\begin{tabular}{l|l}
\hline \multicolumn{2}{l}{ Dement Geriatr Cogn Disord 2019;48:1-16 } \\
\hline DOI: $10.1159 / 000503445$ & $\begin{array}{l}\text { C } 2019 \text { S. Karger AG, Basel } \\
\text { www.karger.com/dem }\end{array}$ \\
\hline
\end{tabular}

Yorozuya et al.: Review of MNPIs for Dementia
Fig. 1. Literature search and study selection process. RCT, randomized controlled trials.

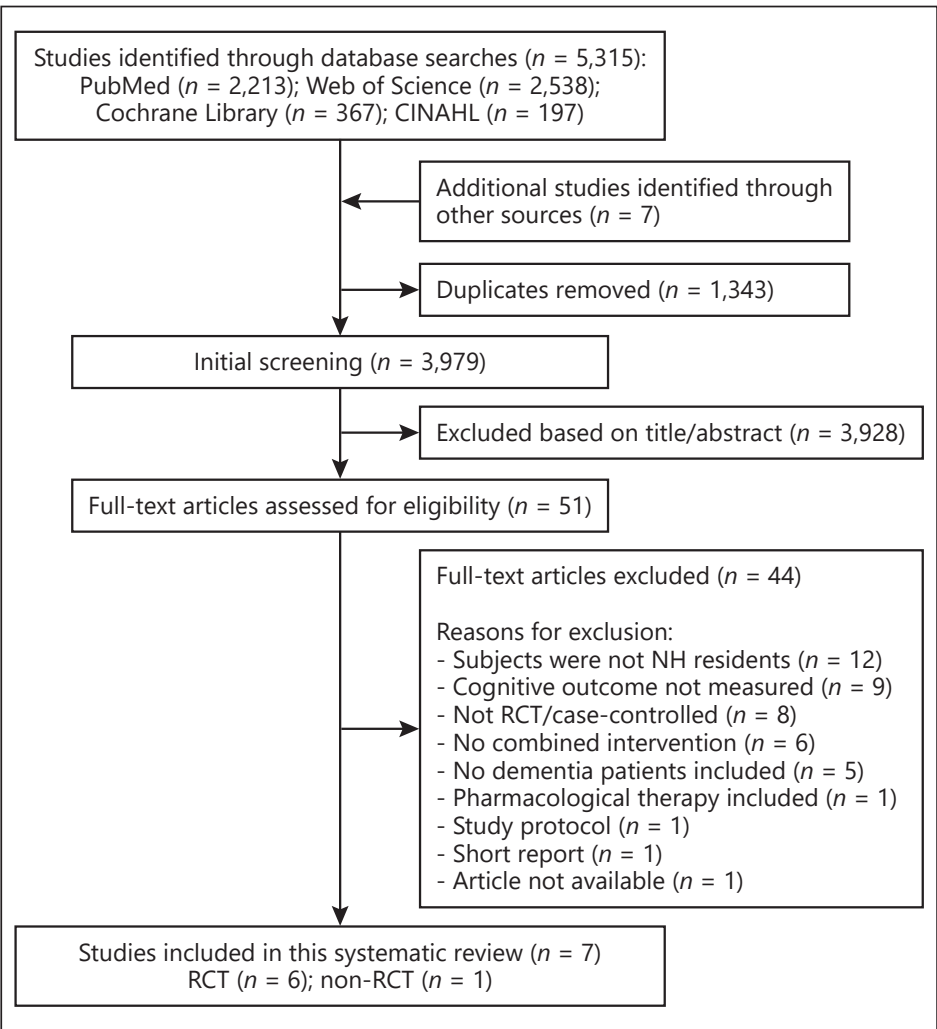

\section{Results}

A total of 5315 studies were extracted through the database search. After screening all records, 51 full-text articles were assessed for eligibility. Finally, 7 studies were included in the systematic review. These included 6 RCTs [15, 25, 41, 52, 53] and one non-RCT [40] (Fig. 1). One RCT and the single non-RCT were conducted by the same team at the same NH $[40,41]$. These were included in the review because the subjects and methods were different and both met our inclusion criteria.

\section{Quality and Level of Evidence of Study}

Three of the included 6 RCTs were scored 3 or less for quality on the Modified Jadad Scale. One article scored 2, 2 articles scored 3, 2 articles scored 5, and 1 article scored 6. One study was published in 2011, 1 in 2012, 1 in 2015, 2 in 2016, and 1 in 2018. Three studies were randomized by random number tables or computer-generated random allocation. There were no double-blinded studies. Three were Ib level of evidence and the other 3 were IIa (Table 1).

The single non-RCT was scored 10 for quality on methodological index for non-randomized studies. This study was published in 2014 and the level of evidence was IIb (Table 2).

\section{Study Characteristics}

The 7 studies included a total of 221 patients. The sample size in these studies ranged from 10 to 66 , and $57.1 \%(n=4)$ had $<30$ subjects. The mean age was 84.0 years old and $78.4 \%(n=173)$ of the patients were female. Three studies took place in The Netherlands, 2 in Germany, 1 in Italy, and 1 in Korea. The types of dementia included Alzheimer's disease, 
Dementia

and Geriatric
Cognitive Disorders
Dement Geriatr Cogn Disord 2019:48:1-16
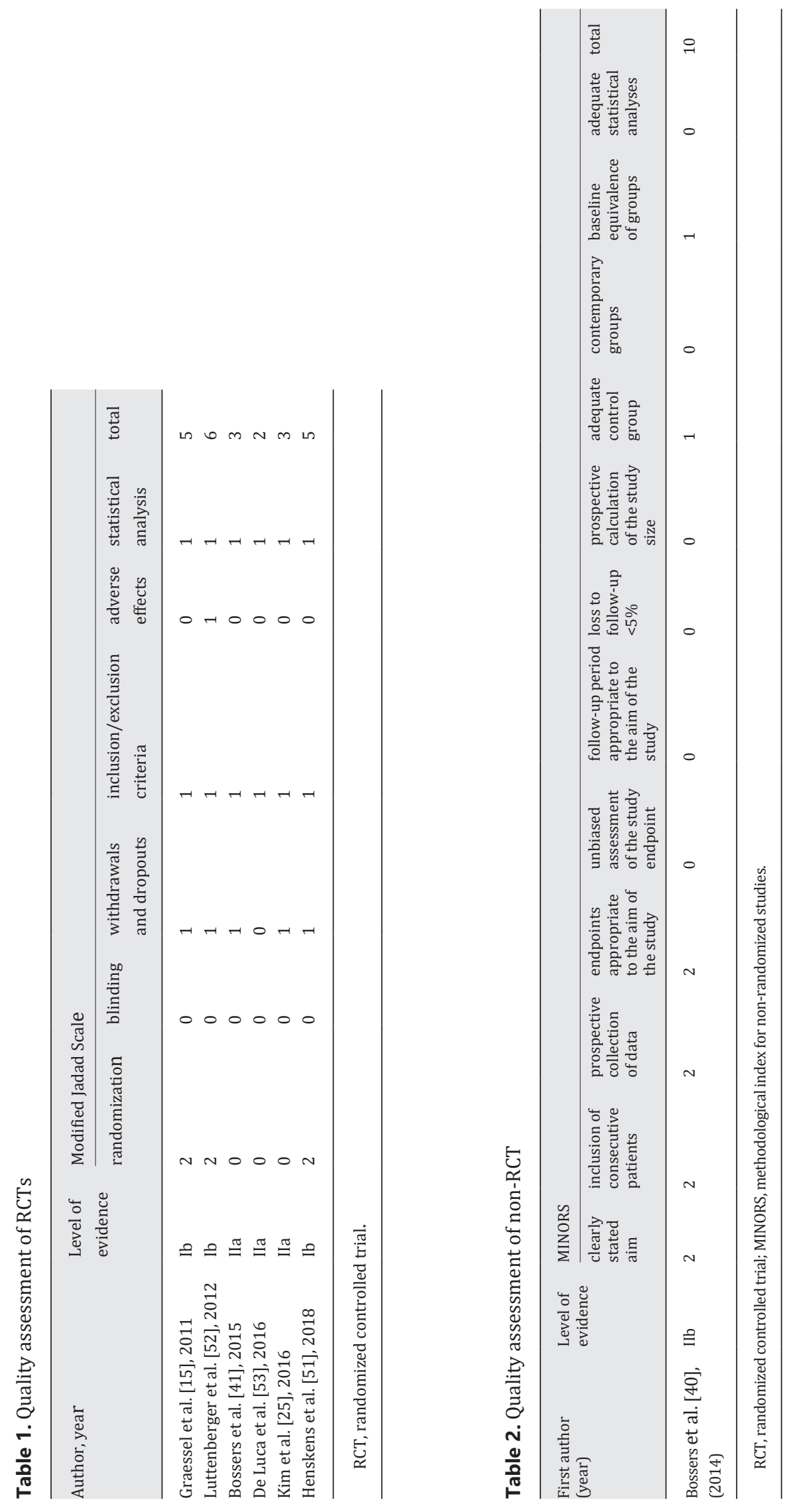

KARGER

Yorozuya et al.: Review of MNPIs for Dementia 
vascular dementia, mixed dementia, progressive dementia (except for vascular and secondary dementia), dementia, and no diagnosis subjects who were judged to have a disease (Table 3 ).

\section{Outcome of MNPI}

Six studies of global cognitive function, 4 studies of executive function, 3 studies of attention, 3 studies of memory, and 1 study of constructional apraxia were identified (Table 4).

\section{Effects of MNPI}

Significant positive effects were reported in 4 studies of global cognitive function, 1 study of executive function, 1 study of attention, 2 studies of memory, and 1 study of constructional apraxia. There were no reports of deterioration (Table 4).

\section{Contents of MNPI}

The types of NPIs used in the MNPI were as follows: 10 exercises, 1 reminiscence, 1 art, 1 horticulture, 1 music, 3 cognitive training, 3 activities of daily living (ADL), 1 neurorehabilitation, 2 spiritual elements, 1 recreation, 1 laughing, 1 activity, and 1 handicraft.

Regarding the number and content of NPIs used in MNPIs, 2 types of NPIs were used in 3 studies: aerobic and strength [40, 41], cognitive training, and neurorehabilitation [53]. Three types of NPIs were used in 1 study: aerobic, strength, and ADL [51]. Four types of NPIs were used in 2 studies: exercise, cognitive training, ADL, and spiritual elements [15, 52]. Ten types of NPIs were used in 1 study: stretching, aerobic, reminiscence, art, horticulture, music, recreation, laughing, activity, and handicrafts (Table 5) [25].

\section{Frequency, Duration, Length and Form of MNPI}

The MNPI had a range of 3-6 times a week, from 6 to 48 weeks, and 30-180 min per session, respectively. The form of MNPI included 4 integrated, 2 divided, and 1 using both forms combined. The most common frequencies were 3 [51, 53], $5[25,40]$, and $6[15,52]$ times a week, the most common duration was 24 weeks $[25,51,52]$, the most common lengths were $30[40,41]$ and $120[15,52]$ min per session, and the most common form was integrated (Table 6) $[15,25,52,53]$.

\section{Discussion}

MNPIs for PWD in NHs included 6 RCTs and one non-RCT. The level of evidence was between Ib and IIb. Three of the included 6 RCTs were scored at 5 or 6 for quality on the Modified Jadad Scale. Therefore, data indicated that these systematic review articles are of high quality.

\section{Outcome and Effect of MNPI}

MNPI seems to improve the global cognitive function, executive function, attention, memory, and constructional apraxia of PWD in NHs [15, 41, 52, 53]. In particular, global cognitive function and memory are considered to be highly reliable because they were reported by RCTs of high quality $[18,19]$.

It has been reported that in dementia preferential intervention should be given to specific cognitive functions such as memory, executive function, visuospatial function, and constructional ability [20-22]. The executive function and memory were consistent with the outcomes of the MNPI in this systematic review. However, MNPI was not used for the outcomes of visuospatial function and constructional ability in this systematic review. In future, studies 
Dementia

and Geriatric
Cognitive Disorders
Dement Geriatr Cogn Disord 2019;48:1-16 DOI: 10.1159/000503445

(c) 2019 S. Karger AG, Basel

www.karger.com/dem

Yorozuya et al.: Review of MNPIs for Dementia

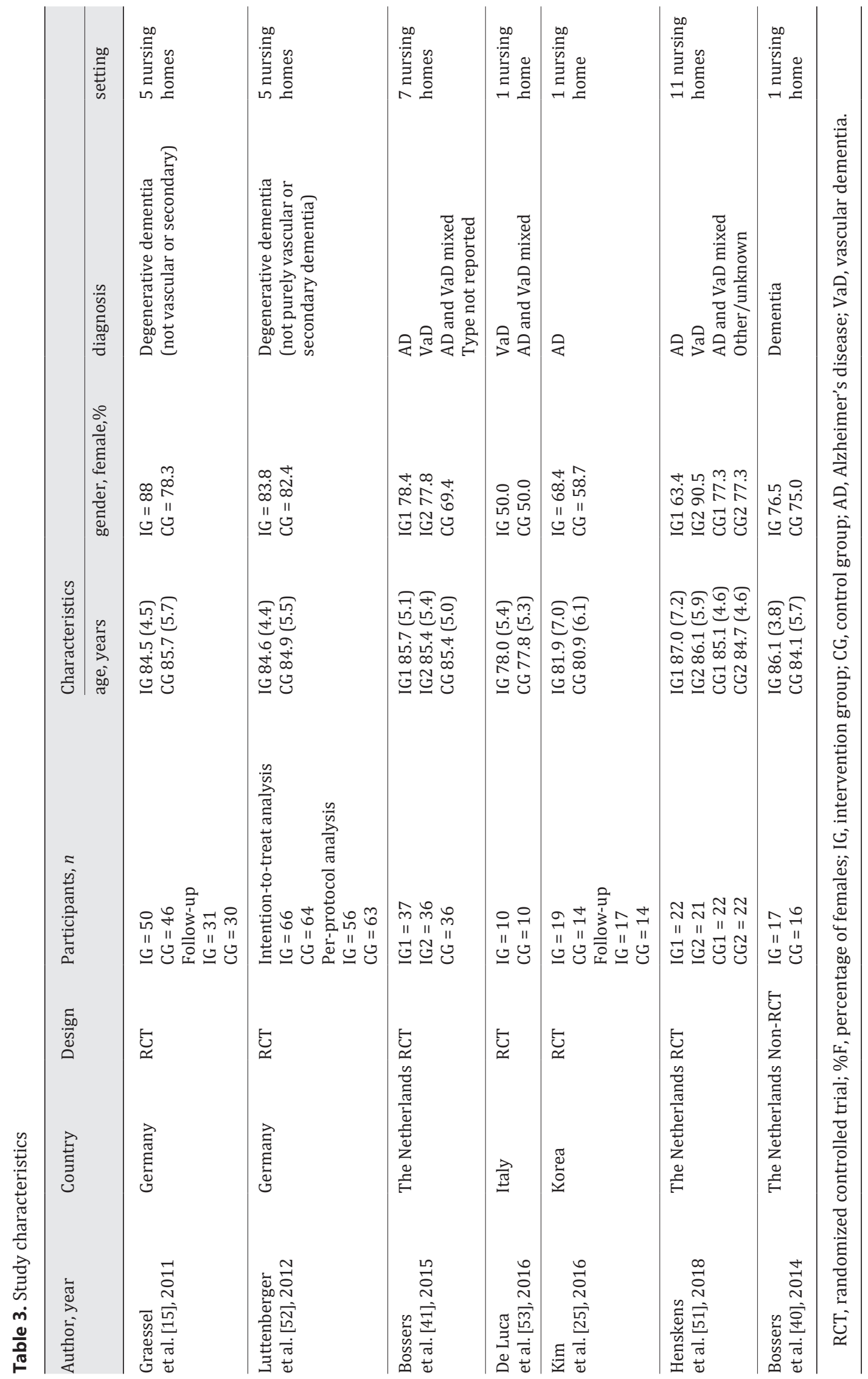


Dementia

Cognitive Disorders
Dement Geriatr Cogn Disord 2019;48:1-16

DOI: 10.1159/000503445

c) 2019 S. Karger AG, Basel

www.karger.com/dem

Yorozuya et al.: Review of MNPIs for Dementia

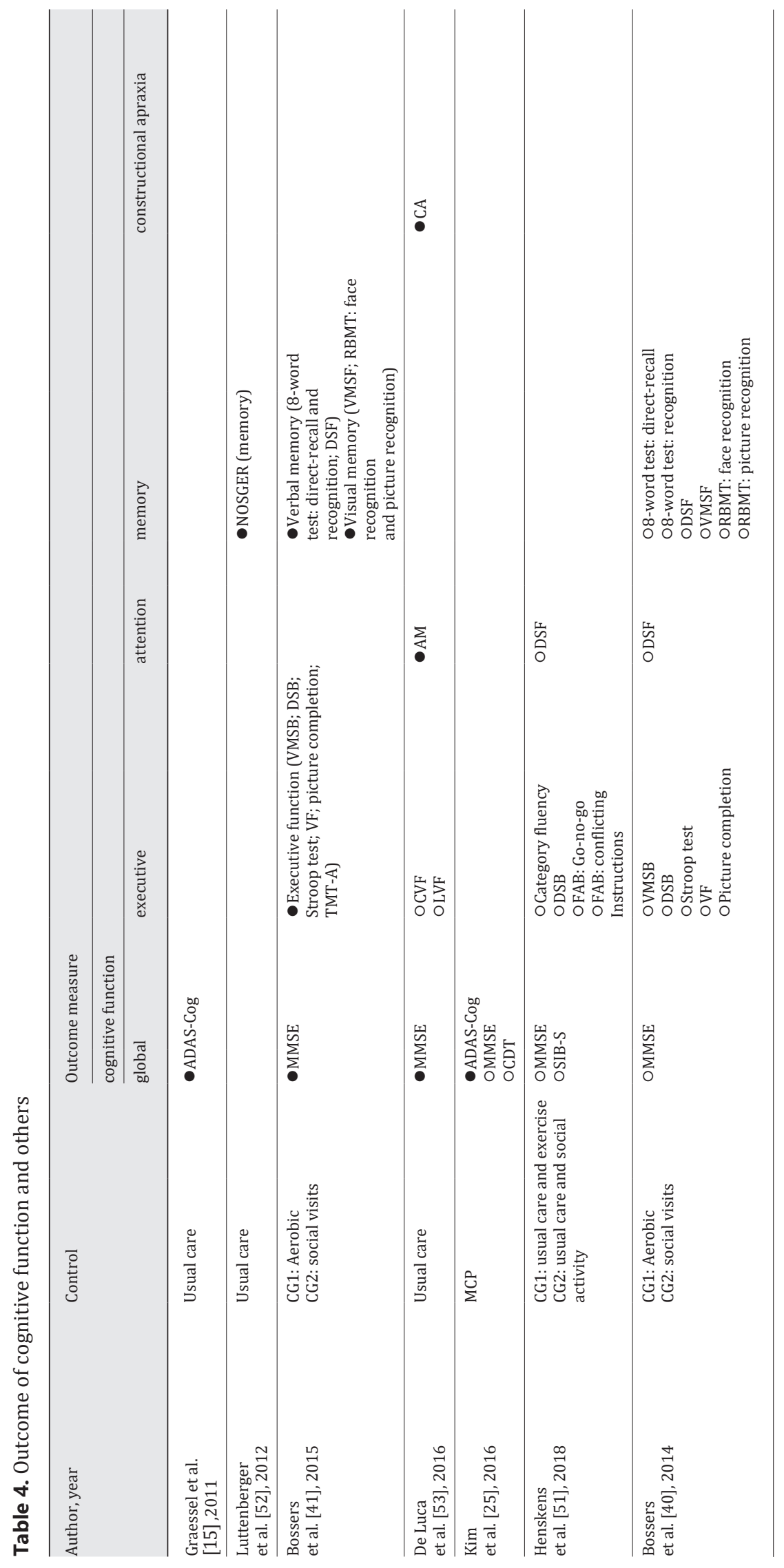


Dementia

and Geriatric
Cognitive Disorders
Dement Geriatr Cogn Disord 2019;48:1-16 DOI: $10.1159 / 000503445$

(c) 2019 S. Karger AG, Basel

www.karger.com/dem

Yorozuya et al.: Review of MNPIs for Dementia
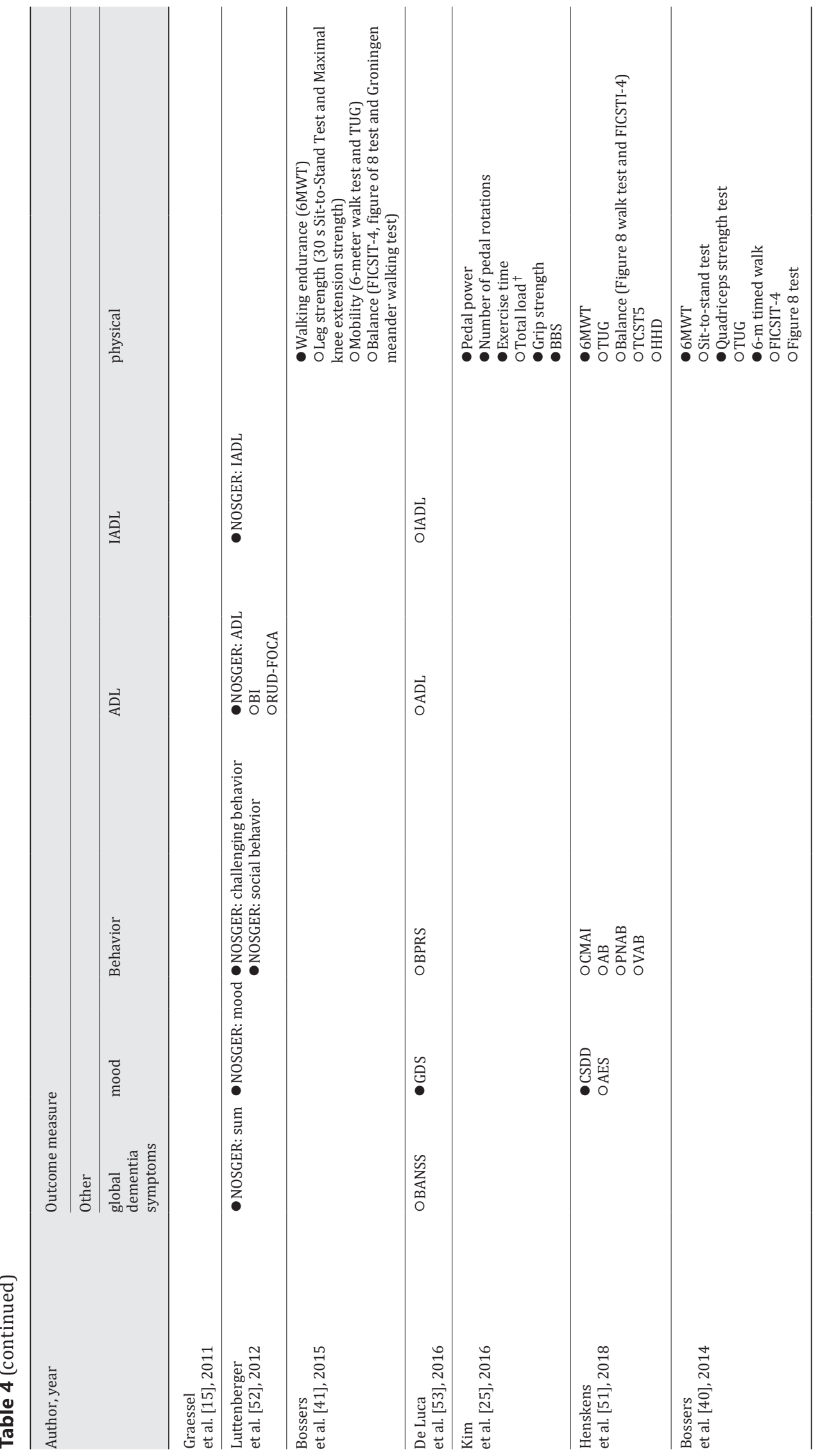

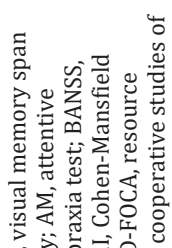

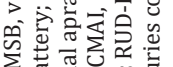

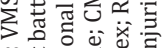

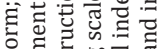

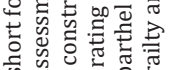

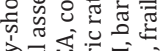

可

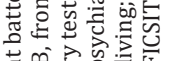

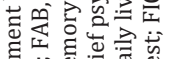

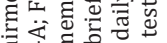

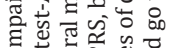

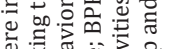

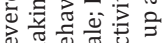

ज.

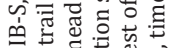

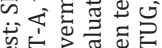

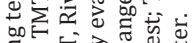

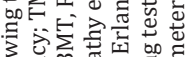

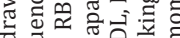

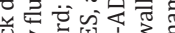

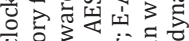

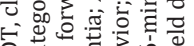

ชิ

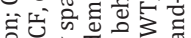

岁

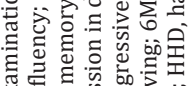

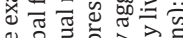

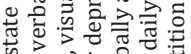

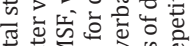

:

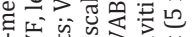

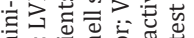

घ 3 त

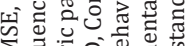

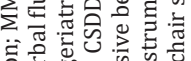

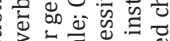

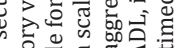

응

政

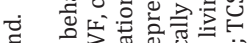

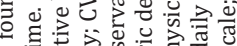

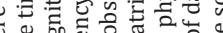

3 .

舟

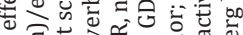

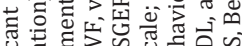

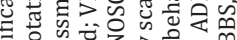

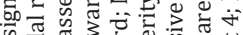

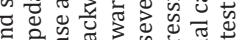

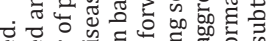

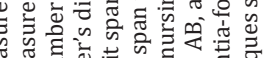

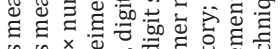

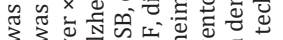

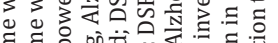
E

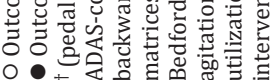




\begin{tabular}{l|l}
\hline DOI: $10.1159 / 000503445$ & $\begin{array}{l}\text { @ 2019 S. Karger AG, Basel } \\
\text { www.karger.com/dem }\end{array}$ \\
\hline
\end{tabular}

Table 5. Contents of MNPI

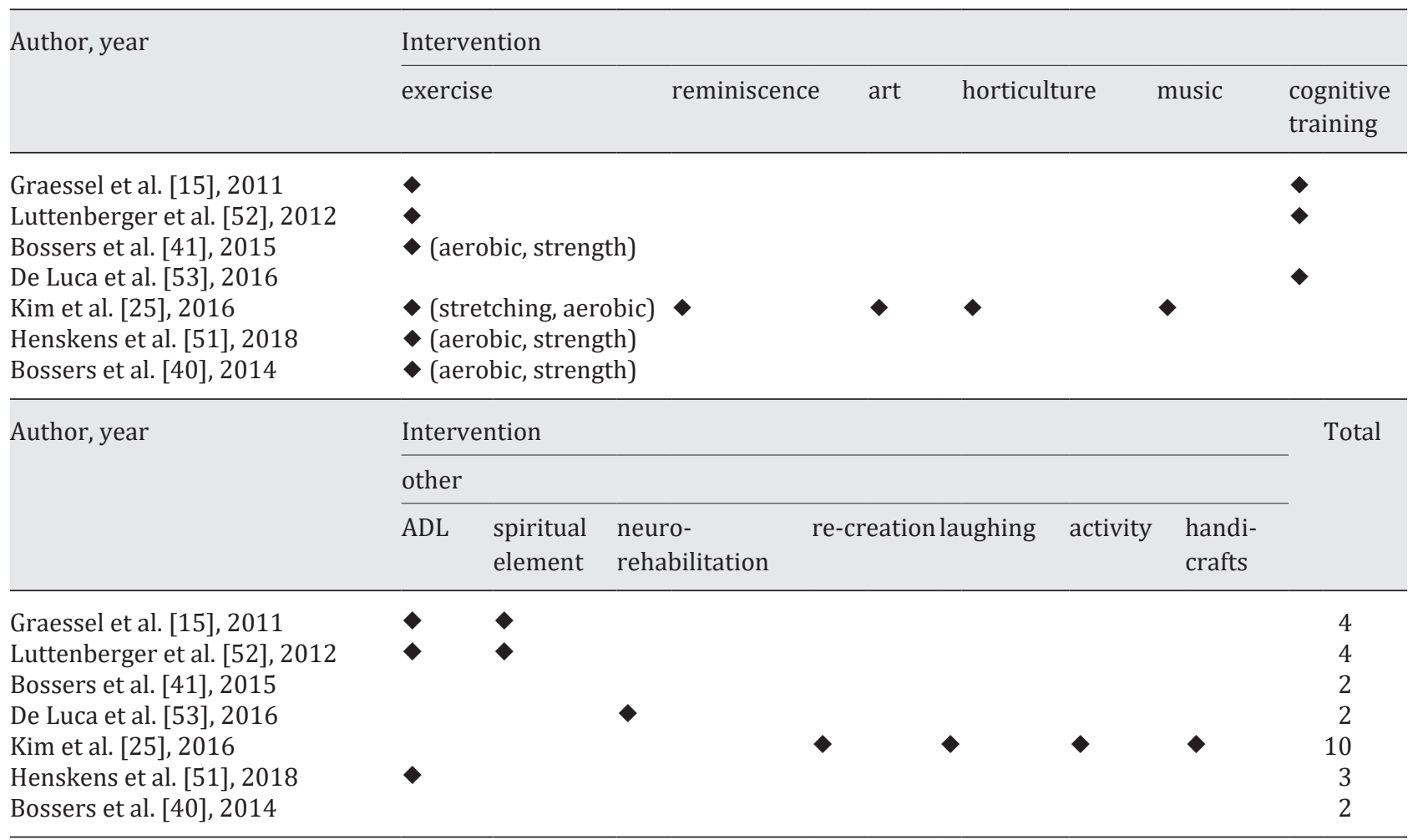

- Non-pharmacological intervention was used.

MNPI, multimodal non-pharmacological intervention; ADL, activities of daily living.

including visuospatial function and constructional ability are needed to enhance the clinical effectiveness of MNPI.

\section{Contents of MNPI}

Improvements in global cognitive function and memory have been reported for interventions involving exercise, cognitive training, ADL, and spiritual elements [15, 52]. From the results of this systematic review, exercise, cognitive training, and ADL tended to be particularly easy to use $[15,52,53]$. Improvement of executive function was reported with exercise incorporating aerobic activity and strength training [40, 41]. Improvement of attention and constructional apraxia was reported with cognitive training [53]. Therefore, the combination of exercise, cognitive training, and ADL may be effective in improving the global and specific cognitive functions of PWD in NHs. In addition, the combination of exercise, cognitive training, and ADL has an effect of promoting synergistic effects or compensation mechanisms $[25,27$, $30]$. This combination is expected to have a greater effect on the global and specific cognitive functions of PWD in NHs than other MNPIs [26, 31].

In addition, MNPIs that include activities such as music and art may improve the global cognitive function of PWD in NHs [25]. However, in this systematic review, it seems that sufficient data have not been obtained, and further study is necessary.

\section{Frequency, Duration, Length and Form of MNPI}

The characteristics of PWD may differ depending on their environment, such as living in the community or living in a facility $[34,35]$. Therefore, this systematic review focused on 
Dementia

and Geriatric
Cognitive Disorders
Dement Geriatr Cogn Disord 2019;48:1-16 DOI: 10.1159/000503445

(c) 2019 S. Karger AG, Basel

www.karger.com/dem

Yorozuya et al.: Review of MNPIs for Dementia

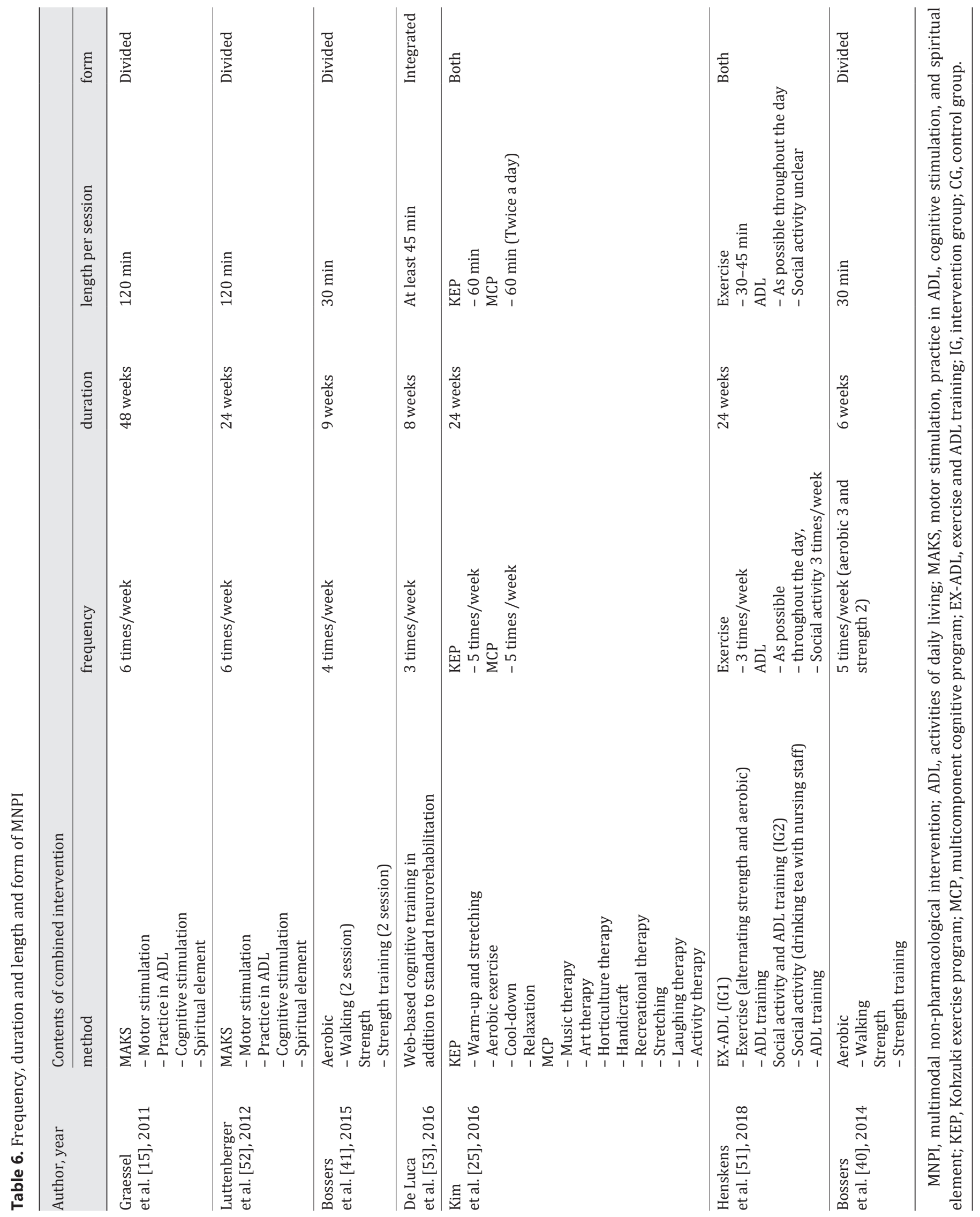


Dementia

Cognitive Disorders \begin{tabular}{l|l}
\hline Dement Geriatr Cogn Disord 2019;48:1-16 \\
\hline DOI: 10.1159/000503445 & $\begin{array}{l}\text { c 2019 S. Karger AG, Basel } \\
\text { www.karger.com/dem }\end{array}$ \\
\hline
\end{tabular}

Yorozuya et al.: Review of MNPIs for Dementia

PWD in NHs. The design of the MNPIs that reported improvement on global or specific cognitive functions was intervention 3-6 times a week, over 8-48 weeks with 30-120 min per session. Many studies had an integrated form of MNPI. These results differ from a previous study that reported improvement effects for cognitive function of PWD with a frequency of 1-2 times a week over 6-52 weeks with 90-210 min per session [18].

Therefore, in MNPI for global or specific cognitive function in PWD in NHs, it may be effective for the intervention design to include a frequency of at least 3 times a week over at least 8 weeks with at least 30 min per session utilizing an integrated form.

\section{Limitations}

The MNPIs cannot be defined as consistent interventions through this study because of the diversity of nomenclature in multimodal studies. Therefore, the search strategies used in this study may be insufficient. In addition, studies that did not express or describe the intervention in detail may have led to misclassification.

Regarding outcomes, specific cognitive functions such as visuospatial function and constructional ability, which are considered to be important as interventions for dementia, were not sufficiently extracted. Therefore, the effects of MNPIs on specific cognitive functions still need to be examined.

In addition, publication bias could not be evaluated sufficiently because there were no reports on the deterioration of global and specific cognitive functions.

\section{Conclusion}

This systematic review suggests that MNPI may improve the global and specific cognitive functions of PWD in NHs. In addition, there were no reports of deterioration. The combination of exercise, cognitive training and ADL, and an intervention design of at least 3 times a week, over at least 8 weeks, with at least 30 min per session using an integrated form is recommended for improving the global and specific cognitive functions of PWD in NHs. This systematic review will be a valuable resource for the development of care practices in $\mathrm{NH}$.

\section{Acknowledgement}

The authors would like to acknowledge Hagijisei Hospital, Hiroshima University, and Seijoh University for supporting the postgraduate study undertaken by the first author.

\section{Disclosure Statement}

The authors have no conflicts of interest to declare.

\section{Funding Sources}

This research received no specific grant from any funding agency in the public, commercial, or not-forprofit sectors. 
Yorozuya et al.: Review of MNPIs for Dementia

\section{Author Contributions}

K.Y.: designed the study and wrote the initial draft of the manuscript. K.Y. and Y.K.: contributed to data collection, extraction and interpretation, and assisted in the preparation of the manuscript. All other authors contributed to the interpretation of data and critically reviewed the manuscript. All authors approved the final version of the manuscript, and agreed to be accountable for all aspects of the work.

\section{References}

1 Wilson RS, McCann JJ, Li Y, Aggarwal NT, Gilley DW, Evans DA. Nursing home placement, day care use, and cognitive decline in Alzheimer's disease. Am J Psychiatry. 2007 Jun;164(6):910-5.

2 Abrahamson K, Clark D, Perkins A, Arling G. Does cognitive impairment influence quality of life among nursing home residents? Gerontologist. 2012 Oct;52(5):632-40.

3 Cohen-Mansfield J, Marx MS, Rosenthal AS. Dementia and agitation in nursing home residents: how are they related? Psychol Aging. 1990 Mar;5(1):3-8.

4 Fernández M, Gobartt AL, Balañá M.; COOPERA Study Group. Behavioural symptoms in patients with Alzheimer's disease and their association with cognitive impairment. BMC Neurol. 2010 Sep;10:87.

5 de Souto Barreto P, Cesari M, Denormandie P, Armaingaud D, Vellas B, Rolland Y. Exercise or Social Intervention for Nursing Home Residents with Dementia: A Pilot Randomized, Controlled Trial. J Am Geriatr Soc. 2017 Sep;65(9):E123-9.

6 World Health Organization [Internet]. Dementia. [cited 2017 Dec 12]. Available from: https://www.who.int/ en/news-room/fact-sheets/detail/dementia.

7 Tariot PN, Cummings JL, Katz IR, Mintzer J, Perdomo CA, Schwam EM, et al. A randomized, double-blind, placebo-controlled study of the efficacy and safety of donepezil in patients with Alzheimer's disease in the nursing home setting. J Am Geriatr Soc. 2001 Dec;49(12):1590-9.

8 Jelic V, Haglund A, Kowalski J, Langworth S, Winblad B. Donepezil treatment of severe Alzheimer's disease in nursing home settings. A responder analysis. Dement Geriatr Cogn Disord. 2008;26(5):458-66.

9 Knight R, Khondoker M, Magill N, Stewart R, Landau S. A Systematic Review and Meta-Analysis of the Effectiveness of Acetylcholinesterase Inhibitors and Memantine in Treating the Cognitive Symptoms of Dementia. Dement Geriatr Cogn Disord. 2018;45(3-4):131-51.

10 Loy C, Schneider L. Galantamine for Alzheimer's disease and mild cognitive impairment. Cochrane Database Syst Rev. 2006 Jan;(1):CD001747.

11 Raschetti R, Albanese E, Vanacore N, Maggini M. Cholinesterase inhibitors in mild cognitive impairment: a systematic review of randomised trials. PLoS Med. 2007 Nov;4(11):e338.

12 Sadowsky $\mathrm{CH}$, Galvin JE. Guidelines for the management of cognitive and behavioral problems in dementia. J Am Board Fam Med. 2012 May-Jun;25(3):350-66.

13 Cooper C, Li R, Livingston G. A systematic review of treatments for Mild Cognitive Impairment. Br J Psychiatry. 2013 Sep;203(3):255-64.

14 Livingston G, Sommerlad A, Orgeta V, Costafreda SG, Huntley J, Ames D, et al. Dementia prevention, intervention, and care. Lancet. 2017 Dec;390(10113):2673-734.

15 Graessel E, Stemmer R, Eichenseer B, Pickel S, Donath C, Kornhuber J, et al. Non-pharmacological, multicomponent group therapy in patients with degenerative dementia: a 12-month randomizied, controlled trial. BMC Med. 2011 Dec;9:129.

16 Kurz AF, Leucht S, Lautenschlager NT. The clinical significance of cognition-focused interventions for cognitively impaired older adults: a systematic review of randomized controlled trials. Int Psychogeriatr. 2011 Nov; 23(9):1364-75.

17 Woods B, Spector A, Jones C, Orrell M, Davies S. Reminiscence therapy for dementia. Cochrane Database Syst Rev. 2005 Apr;(2):CD001120.

18 Olazarán J, Reisberg B, Clare L, Cruz I, Peña-Casanova J, Del Ser T, et al. Nonpharmacological therapies in Alzheimer's disease: a systematic review of efficacy. Dement Geriatr Cogn Disord. 2010;30(2):161-78.

19 Vasionytė I, Madison G. Musical intervention for patients with dementia: a meta-analysis. J Clin Nurs. 2013 May;22(9-10):1203-16.

20 Wiederman MW, Morgan CD. The Neurobehavioral Cognitive Status Exam (NCSE) with Geriatric Inpatients. Clin Gerontol. 1995;15(4):37-41.

21 Yu F, Kolanowski AM, Strumpf NE, Eslinger PJ. Improving cognition and function through exercise intervention in Alzheimer's disease. J Nurs Scholarsh. 2006;38(4):358-65.

22 Tsuruoka Y, Takahashi M, Suzuki M, Sato K, Shirayama Y. Utility of the Neurobehavioral Cognitive Status Examination (COGNISTAT) in differentiating between depressive states in late-life depression and late-onset Alzheimer's disease: a preliminary study. Ann Gen Psychiatry. 2016 Jan;15(3):3.

23 Farina E, Fioravanti R, Chiavari L, Imbornone E, Alberoni M, Pomati S, et al. Comparing two programs of cognitive training in Alzheimer's disease: a pilot study. Acta Neurol Scand. 2002 May;105(5):365-71.

24 Schneider N, Yvon C. A review of multidomain interventions to support healthy cognitive ageing. J Nutr Health Aging. 2013 Mar;17(3):252-7. 
25 Kim MJ, Han CW, Min KY, Cho CY, Lee CW, Ogawa Y, et al. Physical Exercise with Multicomponent Cognitive Intervention for Older Adults with Alzheimer's Disease: A 6-Month Randomized Controlled Trial. Dement Geriatr Cogn Disord Extra. 2016 Jun;6(2):222-32.

26 De Oliveira TC, Soares FC, De Macedo LD, Diniz DL, Bento-Torres NV, Picanço-Diniz CW. Beneficial effects of multisensory and cognitive stimulation on age-related cognitive decline in long-term-care institutions. Clin Interv Aging. 2014 Feb;9:309-20.

27 Liang CK, Chou MY, Chen LY, Wang KY, Lin SY, Chen LK, et al. Delaying cognitive and physical decline through multidomain interventions for residents with mild-to-moderate dementia in dementia care units in Taiwan: A prospective cohort study. Geriatr Gerontol Int. 2017 Apr;17 Suppl 1:36-43.

28 Han JW, Lee H, Hong JW, Kim K, Kim T, Byun HJ, et al. Multimodal Cognitive Enhancement Therapy for Patients with Mild Cognitive Impairment and Mild Dementia: A Multi- Center, Randomized, Controlled, Double-Blind, Crossover Trial. J Alzheimers Dis. 2017;55(2):787-96.

29 Kim HJ, Yang Y, Oh JG, Oh S, Choi H, Kim KH, et al. Effectiveness of a community-based multidomain cognitive intervention program in patients with Alzheimer's disease. Geriatr Gerontol Int. 2016 Feb;16(2):191-9.

30 Cotelli M, Manenti R, Zanetti O, Miniussi C. Non-pharmacological intervention for memory decline. Front Hum Neurosci. 2012 Mar;6:46.

31 Hosseini SM, Kramer JH, Kesler SR. Neural correlates of cognitive intervention in persons at risk of developing Alzheimer's disease. Front Aging Neurosci. 2014 Aug;6:231.

32 Wilson RS, Mendes De Leon CF, Barnes LL, Schneider JA, Bienias JL, Evans DA, et al. Participation in cognitively stimulating activities and risk of incident Alzheimer disease. JAMA. 2002 Feb;287(6):742-8.

33 Chalfont G, Milligan C, Simpson J. A mixed methods systematic review of multimodal non-pharmacological interventions to improve cognition for people with dementia. Dementia (London). 2018, Epub ahead of print.

34 Folkerts AK, Roheger M, Franklin J, Middelstädt J, Kalbe E. Cognitive interventions in patients with dementia living in long-term care facilities: systematic review and meta-analysis. Arch Gerontol Geriatr. 2017 Nov; 73: 204-21.

35 Wang G, Albayrak A, Van Der Cammen TJ. A systematic review of non-pharmacological interventions for BPSD in nursing home residents with dementia: from a perspective of ergonomics. Int Psychogeriatr. 2019 Aug; 31(8):1137-49.

36 te Boekhorst S, Depla MF, de Lange J, Pot AM, Eefsting JA. The effects of group living homes on older people with dementia: a comparison with traditional nursing home care. Int J Geriatr Psychiatry. 2009 Sep;24(9): 970-8.

37 Smith GE, Kokmen E, O'Brien PC. Risk factors for nursing home placement in a population-based dementia cohort. J Am Geriatr Soc. 2000 May;48(5):519-25.

38 Kang HY, Bae YS, Kim EH, Lee KS, Chae MJ, Ju RA. An integrated dementia intervention for Korean older adults. J Psychosoc Nurs Ment Health Serv. 2010 Dec;48(12):42-50.

39 Morley JE, Philpot CD, Gill D, Berg-Weger M. Meaningful activities in the nursing home. J Am Med Dir Assoc. 2014 Feb;15(2):79-81.

40 Bossers WJ, Scherder EJ, Boersma F, Hortobágyi T, van der Woude LH, van Heuvelen MJ. Feasibility of a combined aerobic and strength training program and its effects on cognitive and physical function in institutionalized dementia patients. A pilot study. PLoS One. 2014 May;9(5):e97577.

41 Bossers WJ, van der Woude LH, Boersma F, Hortobágyi T, Scherder EJ, van Heuvelen MJ. A 9-Week Aerobic and Strength Training Program Improves Cognitive and Motor Function in Patients with Dementia: A Randomized, Controlled Trial. Am J Geriatr Psychiatry. 2015 Nov;23(11):1106-16.

42 Rodriguez-Larrad A, Arrieta H, Rezola C, Kortajarena M, Yanguas JJ, Iturburu M, et al. Effectiveness of a multicomponent exercise program in the attenuation of frailty in long-term nursing home residents: study protocol for a randomized clinical controlled trial. BMC Geriatr. 2017 Feb;17(1):60.

43 Liberati A, Altman DG, Tetzlaff J, Mulrow C, Gøtzsche PC, Ioannidis JP, et al. The PRISMA statement for reporting systematic reviews and meta-analyses of studies that evaluate healthcare interventions: explanation and elaboration. BMJ. 2009 Jul;339 jul21 1:b2700.

44 Moher D, Liberati A, Tetzlaff J, Altman DG.; PRISMA Group. Preferred reporting items for systematic reviews and meta-analyses: the PRISMA statement. Int J Surg. 2010;8(5):336-41.

45 Shamseer L, Moher D, Clarke M, Ghersi D, Liberati A, Petticrew M, et al.; PRISMA-P Group. Preferred reporting items for systematic review and meta-analysis protocols (PRISMA-P) 2015: elaboration and explanation. BMJ. 2015 Jan;350 jan02 1:g7647.

46 Jadad AR, Moore RA, Carroll D, Jenkinson C, Reynolds DJ, Gavaghan DJ, et al. Assessing the quality of reports of randomized clinical trials: is blinding necessary? Control Clin Trials. 1996 Feb;17(1):1-12.

47 Oremus M, Wolfson C, Perrault A, Demers L, Momoli F, Moride Y. Interrater reliability of the modified Jadad quality scale for systematic reviews of Alzheimer's disease drug trials. Dement Geriatr Cogn Disord. 2001 May-Jun;12(3):232-6.

48 Wu PL, Lee M, Huang TT. Effectiveness of physical activity on patients with depression and Parkinson's disease: A systematic review. PLoS One. 2017 Jul;12(7):e0181515.

49 Slim K, Nini E, Forestier D, Kwiatkowski F, Panis Y, Chipponi J. Methodological index for non-randomized studies (minors): development and validation of a new instrument. ANZ J Surg. 2003 Sep;73(9):712-6.

50 Shekelle PG, Woolf SH, Eccles M, Grimshaw J. Clinical guidelines: developing guidelines. BMJ. 1999 Feb; 318(7183):593-6. 
51 Henskens M, Nauta IM, van Eekeren MC, Scherder EJ. Effects of Physical Activity in Nursing Home Residents with Dementia: A Randomized Controlled Trial. Dement Geriatr Cogn Disord. 2018;46(1-2):60-80.

52 Luttenberger K, Donath C, Uter W, Graessel E. Effects of multimodal nondrug therapy on dementia symptoms and need for care in nursing home residents with degenerative dementia: a randomized-controlled study with 6-month follow-up. J Am Geriatr Soc. 2012 May;60(5):830-40.

53 De Luca R, Bramanti A, De Cola MC, Leonardi S, Torrisi M, Aragona B, et al. Cognitive training for patients with dementia living in a sicilian nursing home: a novel web-based approach. Neurol Sci. 2016 Oct;37(10):168591. 